\title{
OPTOELECTRONIC DEVICE FOR REMOTE TEMPERATURE CONTROL OF SANITARY UNITS
}

\author{
Sirojiddin Fayozovich Ergashev ${ }^{1}$, \\ Kuchkarov Akmaljon Axmadaliyevich², Mamasadikova Umida Yusupjonovna ${ }^{3}$
}

${ }^{1}$ Doctor of Technical Sciences, Professor of Electronics and Instrumentation department, Ferghana Polytechnic Institute, Ferghana, Uzbekistan

${ }^{2} \mathrm{PhD}$, Head of Electronics and Instrumentation department, Ferghana Polytechnic Institute, Ferghana, Uzbekistan

${ }_{3}^{3}$ Master of Electronics and Instrumentation department, Ferghana Polytechnic Institute, Ferghana, Uzbekistan

Article DOI: https://doi.org/10.36713/epra7317 DOI No: $10.36713 /$ epra7317

\begin{abstract}
ANOTATION
The article discusses the principles of constructing an optoelectronic device without optical systems for remote control of the temperature of solar installations and small objects. A block diagram of the developed device is shown and its principle of action is laid out.
\end{abstract}

KEYWORDS: optoelectronic, temperature, amplitude detector, thermal radiation, spectral density.

\section{INTRODUCTION}

High-performance, economical and safe operation of solar installations requires the use of modern methods and means of measuring quantities that characterize the course of the process and the state of the equipment. Automatic control is logically the first stage of automation, without the successful functioning of which it is impossible to create an automated control system for solar installations.

At high capacities, even the smallest control errors in solar plants result in large absolute energy losses. Therefore, the role of automatic control and management of solar installations is increasing. One of the most pressing problems in solar installations is automatic temperature control. There are many different temperature control devices used in solar technology, but they are mostly contact devices.

The most promising in this sense is the optoelectronic method of temperature control, and in many cases their use turns out to be not only preferable in comparison with contact means for measuring temperature, i.e. thermometers, but the only one possible. This primarily concerns the measurement of the temperature of objects, contact with which is difficult or impossible due to its remoteness or inaccessibility.

\section{MATERIAL AND METHODS}

We have developed an optoelectronic device for remote control of the temperature of small-sized objects, which can be successfully used in the study of the temperature characteristics of solar installations.

The block diagram of the optoelectronic device is shown in Fig. 1.

An optoelectronic device for remote monitoring of the temperature of objects contains a monitoring object 1 , which, through a modulator 2 , is optically connected to the first radiation receiver 3 , the output of which is through the first amplifier 4, the first amplitude detector 5 and the first integrator 6 are connected to the first input of the signal ratio obtaining device 13, the second radiation receiver 7 , the output of which is through the second amplifier 8, the second amplitude detector 9 and the second integrator 10 is connected to the second 
input of the signal ratio acquisition device 13, the output of which is connected with the input of the recording device 14, the control device of the collimated radiation source 12, the input of which is connected to the output of the first amplifier 4, and the output is connected to the input of the collimated radiation source 11 which through reflections from the surface of the controlled object 1 is optically connected to the second radiation receiver 7, the electric motor 15 is a rotor, which is mechanically connected to the axis of rotation of the modulator 2.

Figure 2 shows timing diagrams that explain the principle of operation of the proposed device.

An optoelectronic device for remote control of the temperature of objects operates as follows. The heat

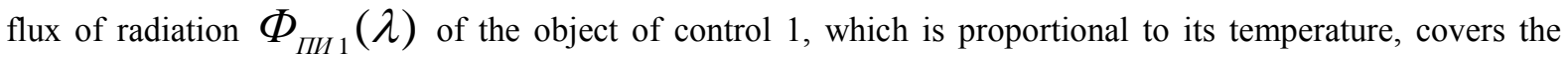
distance 1 , is modulated by modulator 2 and enters the sensitive area of the first radiation receiver. The flux entering the sensitive area of the first radiation detector according to the theory of optoelectronic devices $[1,3,6]$ is defined as:

$$
\Phi_{\text {пи } 1}(\lambda)=\tau_{c}(\lambda) M \kappa o(\lambda) \frac{A_{\kappa o} D_{\Pi И 1}^{2}}{4 l^{2}}
$$

where: $\tau_{c}(\lambda)$ - spectral transmittance of the atmosphere; $M_{\kappa o}(\lambda)$ - spectral density of the radiant luminosity of the emitting surface of the controlled object; $A_{\kappa O}$ - the area of the emitting surface of the controlled object; $D_{П И 1}$ - the diameter of the entrance pupil of the first radiation detector; $l$ - the distance between the controlled object and the first photodetector.

Taking into account that $M_{\kappa o}(\lambda)=\varepsilon_{\kappa o}(\lambda) M_{ч T}(\lambda)$ expression (1) will take the form:

$\Phi_{\text {Пи } 1}(\lambda)=\tau_{c}(\lambda) \varepsilon_{\kappa о}(\lambda) M_{\text {чт }}(\lambda) \frac{A_{\kappa o} D_{\Pi И 1}^{2}}{4 l^{2}}$,

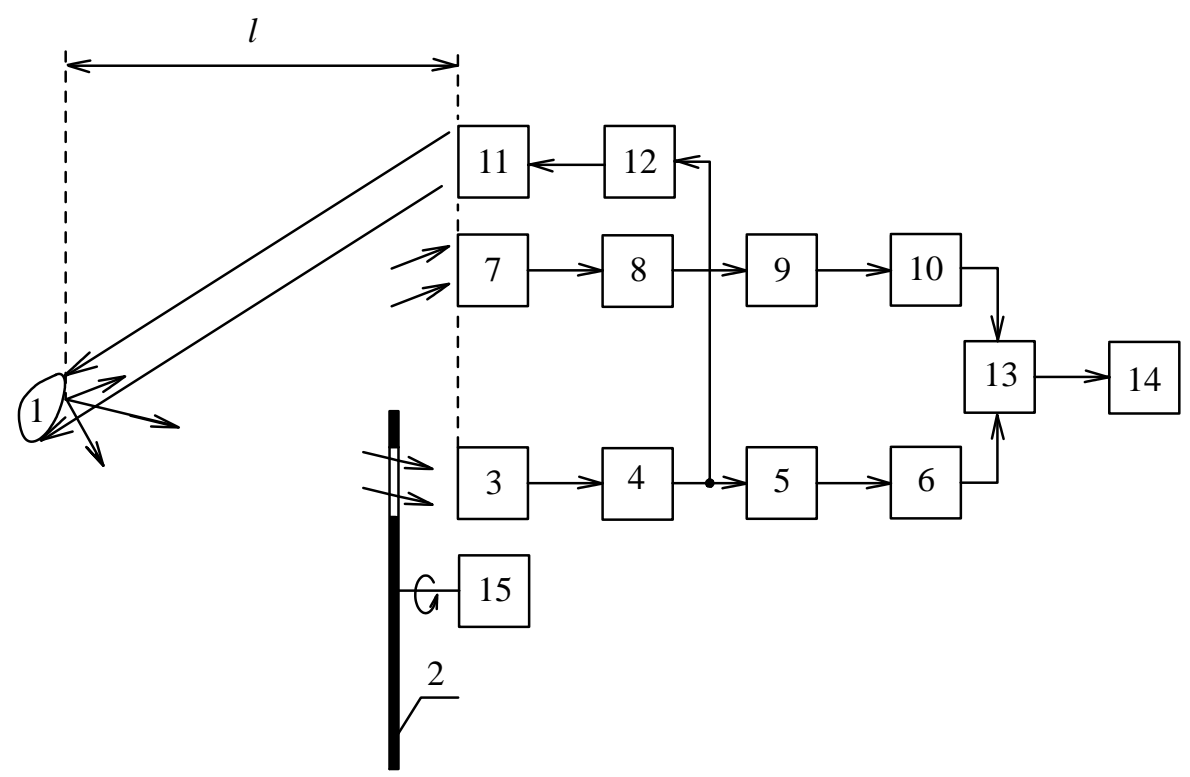

Fig. 1. Block diagram of an optoelectronic device for remote temperature control of solar installations.

where: $\varepsilon_{\kappa O}(\lambda)$ - spectral coefficient of thermal radiation of the controlled object; $M_{Y T}(\lambda)$ - the spectral density of the energy luminosity of the black body.

Considering that the radiation receiver operates in a limited spectral range, then expressions (2) for wavelengths $\lambda 1 m$ which corresponds to the maximum sensitivity of the first radiation receiver can be written as:

$$
\Phi_{\lambda 1 m_{\Pi И} 1}=\tau_{\lambda 1 m c} \varepsilon_{\lambda 1 m_{\kappa o}} M_{\lambda 1 m 4 T} \frac{A_{\kappa o} D_{\Pi И 1}^{2}}{4 l^{2}}
$$


where: $\varepsilon_{\lambda 1 m_{\kappa o}}$ - spectral coefficient of thermal radiation of the controlled object at wavelengths $\lambda 1 \mathrm{~m}$; $M_{\lambda 1 \mathrm{~m} \mathrm{~T}^{-}}{ }^{-}$the spectral density of the radiant luminosity of a black body at wavelengths $\lambda 1 \mathrm{~m} ; \tau_{\lambda 1 \mathrm{mc}}{ }^{-}$ atmospheric transmittance at wavelengths $\lambda 1 \mathrm{~m}$.

Taking into account the Stefan-Boltzmann law that $M_{\lambda 1 m \Psi T}=\sigma T^{4}$ expression (3) will take the form:

$$
\Phi_{\lambda 1 m_{\Pi и} 1}=\tau_{\lambda 1 m c} \mathcal{E}_{\lambda 1 m_{\kappa o}} \sigma T^{4} \frac{A_{\kappa o} D_{\Pi И 1}^{2}}{4 l^{2}}
$$

Where; $\mathrm{T}$ - the temperature of the controlled object; $\sigma=5,6697 \cdot 10^{-8} \mathrm{Bm} \cdot \mathcal{M}^{-2} \cdot \mathrm{K}^{-4}$

- Stefan - Boltzmann constant.

The voltage corresponding to expression (4) from the output of the first radiation receiver 3 is amplified by the first amplifier 4 , as a result of which an alternating electrical signal is formed at its output (Fig. 2 c), which is fed to the input of the control device of the collimated radiation source 12 and the first amplitude detector 5. The detected signal (Fig. 2 e), from the output of the first amplitude detector 5 is integrated by the first integrator 6 and fed to the first input of the device for obtaining the ratio of signals 13. In this case, the voltage applied to the first input of the device, obtaining the signal ratios 13 can be defined as:

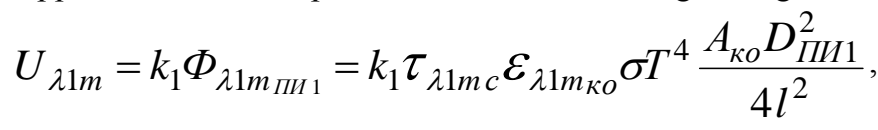

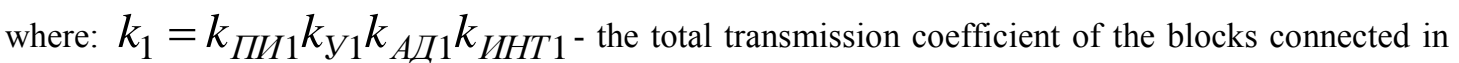
series with the first radiation receiver 3 , the first amplifier 4 , the first amplitude detector 5 and the first integrator 6; $k_{П И 1}$ - the transmission coefficient of the first radiation receiver; $k_{Y 1}$ - the transmission coefficient of the first amplifier; $k_{А Д 1}$ - transmission coefficient of the first amplitude detector; $k_{И Н T 1^{-}}$transmission coefficient of the first integrator.

When the output signal of the first amplifier 4 acts on the input of the control device of the collimated radiation source 12, an antiphase electrical signal is formed at its output. The latter is fed to the input of the collimated radiation source 11 and causes a pulsed flow of collimated radiation at its output.

Formed flow, the source of collimated radiation 11 is directed to the area of the controlled object 1 . In this case, the flow reaching on the surface of the controlled object 1 in the case $A_{\kappa о} \leq A_{\kappa И}$ defined as:

$$
\Phi_{\kappa o \lambda 2}=\tau_{\lambda 2 m_{c}} \Phi_{o \lambda 2} \frac{A_{\kappa o}}{A_{\kappa u}}
$$

where: $A_{\kappa u^{-}}$-cross-sectional area of collimated radiation; $\tau_{\lambda 2 m c}$ - the transmittance of the atmosphere at wavelengths $\lambda 2 m ; \Phi_{o \lambda 2}$ - the initial flux of collimated radiation. In this case, the reflected flux from the surface of the controlled object 1 is determined as:

$$
\Phi_{\text {ОТР } \lambda 2}=\gamma_{\kappa o} \tau_{\lambda 2 m_{C}} \Phi_{o \lambda 2} \frac{A_{\kappa o}}{A_{\kappa u}}
$$

where: $\gamma_{\kappa o}$ - coefficient of reflection from the surface of the controlled object at wavelengths $\lambda 2$.

Then the expression for the flux that reaches the sensitive area of the second radiation detector 7 has the form:

$\Phi_{\lambda 2 m \Pi И 2}=\gamma_{\kappa o} \tau_{\lambda 2 m c}^{2} \Phi_{o \lambda 2} \frac{A_{\kappa o}}{A_{\kappa u}} \frac{D_{\Pi И 2}^{2}}{4 l^{2}}$,

where: $D_{\text {ПИ } 2}$ - the diameter of the entrance pupil of the second radiation detector. 


\section{DISCUSSION RESULTS}

The voltage corresponding to expression (8) from the output of the second radiation detector 7 is amplified by the second amplifier 8 , as a result of which an alternating electrical signal is formed at its output (Fig. 2 d), which is fed to the input of the second amplitude detector 9. The detected signal (Fig. 2 f) c the output of the second amplitude detector 9 is integrated by the second integrator 10 and fed to the second input of the device for obtaining the ratio of signals 13 .

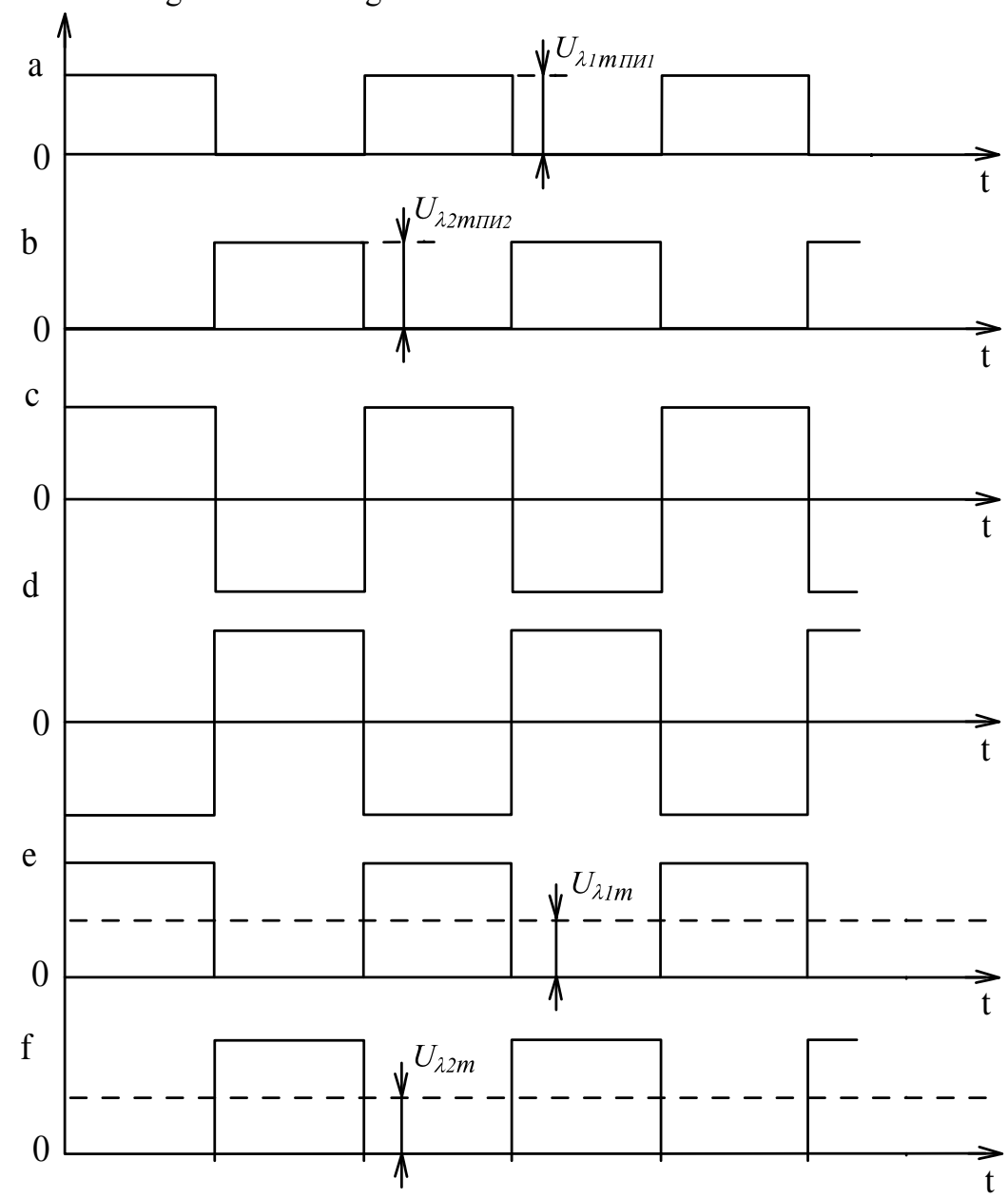

Fig. 2. Timing diagrams of an optoelectronic device.

In this case, the voltage supplied to the second input of the device for obtaining the ratio of signals 13 can be determined as:

$$
U_{\lambda 2 m}=k_{2} \Phi_{\lambda 2 m \Pi И 2}=k_{2} \gamma_{\kappa o} \tau_{\lambda 2 m c}^{2} \Phi_{o \lambda 2} \frac{A_{\kappa o}}{A_{\kappa и}} \frac{D_{\Pi И 2}^{2}}{4 l^{2}},
$$

where: $k_{2}=k_{Ф \Pi 2} k_{У 2} k_{A Д 2} k_{И Н Т 2}$ - the total transmission coefficient of blocks connected in series with the second receiver of radiation 7, the second amplifier 8, the second amplitude detector 9 and the second integrator $10 ; k_{\Phi \Pi 2^{-}}$the transmission coefficient of the second radiation receiver; $k_{Y 2^{-}}$the transmission coefficient of the second amplifier; $k_{А Д 2}$ - the transmission coefficient of the second amplitude

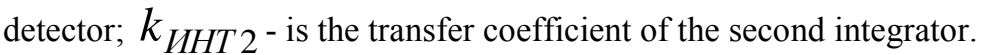

It is known that optical devices intended for temperature measurement mainly use the transparent region of the atmosphere spectrum $[2,4,7]$. 
Therefore, for a small distance between the controlled object and the radiation receiver, it can be considered that $\tau_{\lambda 1 m c}=\tau_{\lambda 2 m c} \approx 1$. Then when using identical electronic units for radiation fluxes

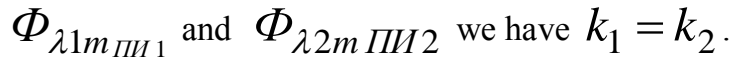

Therefore, at the output, the device for obtaining the ratio of signals 13 , proportional to the temperature of the controlled object 1 , forms the voltage ratio:

$$
\begin{aligned}
& \frac{U_{\lambda 1 m}}{U_{\lambda 2 m}}=\frac{A_{\kappa u} \varepsilon_{\lambda 1 m c} \sigma T^{4}}{\gamma_{\kappa o} \Phi_{o \lambda 2}}, \\
& \text { or } \\
& \frac{U_{\lambda 1 m}}{U_{\lambda 2 m}}=k T^{4},
\end{aligned}
$$

where: $k=\frac{A_{\kappa u} \varepsilon_{\lambda 1 m c} \sigma}{\gamma_{\kappa o} \Phi_{o \lambda 2}}$ - constant value. Since solar parabolic concentrators have the coefficient of reflection of the surface of the heat receiver in the near and mid-IR spectral range is constant and amounts to $\gamma_{\lambda 2 \kappa O}=0,1$.

Then the temperature of the controlled object is determined as:

$$
T_{\kappa o}=\sqrt[4]{\frac{1}{k} \frac{U_{\lambda 1 m}}{U_{\lambda 2 m}}}
$$

Thus, it can be seen from the last expression that the temperature of the controlled object is proportional to the voltage ratio $U_{\lambda 1 m}$ and $U_{\lambda 2 m}$ which is recorded by the recorder, where $k$ is accounted for.

\section{CONCLUSIONS}

An important advantage of an optoelectronic device for remote control of the temperature of solar installations is that with the help of this device it is possible to control the temperature with high accuracy when studying the temperature characteristics of solar installations.

\section{REFERENCES}

1. Yakushenkov Yu.G. Teoriya i raschyot optikoelektronnyh priborov. M.: - Logos, 1999.-480s.

2. Fuks-Rabinovich L.I., Epifanov M.V. Optikoelektronnye pribory. L.: - «Mashinostroenie», 1979.-362 s.

3. A.V. Baholdin, G.E. Romanova, G.I. Cukanova Teoriya i metody proektirovaniya opticheskih sistem. Pod redakciei prof. A.A. Shehonina-SPb: SPb NIU ITMO, 2011. - $104 \mathrm{~s}$

4. Lebed'ko E.G. Sistemy opticheskoi lokacii, chast' 3.-SPb: NIU ITMO, 2013. - 110 s.

5. A. P. Grammatin, G. E. Romanova, O.N. Balacenko. Raschet i avtomatizaciya

6. proektirovaniya opticheskih sistem. - SPb: NIU ITMO, 2013. - $128 \mathrm{~s}$.

7. A.V. Prokof'ev, Metrologiya optiko-elektronnogo priborostroeniya. - SPb: NIU ITMO, 2012. -103 s.

8. V. V. Korotaev, G.S. Mel'nikov, S. V. Miheev, V. M. Samkov, YU. I. Soldatov. Osnovy teplovideniya - SPb: NIU ITMO, 2012 - $122 \mathrm{~s}$. 